\title{
A RING C7 CHROMOSOME IN A MENTALLY AND PHYSICALLY RETARDED MALE WITH VARIOUS SOMATIC ABNORMALITIES
}

\author{
Shuji NaKano and Nariaki MiYamoto \\ First Department of Medicine, Kyushu University \\ School of Medicine, Fukuoka, Japan
}

\begin{abstract}
Summary A 19-year-old mentally and physically retarded male with multiple congenital malformations was found to have a ring configuration of No. 7 chromosome by Giemsa-banding technique. Comparison of the phenotypes with previously reported 2 cases with rings of chromosome 7 shows that the only features in common in these 3 are microcephaly, short stature and hemangioma on the forehead.

His mother showed some structural aberrations of chromosomes in the peripheral lymphocytes. Cytogenetic significance and mother-child relationship of these findings are discussed.
\end{abstract}

\section{INTRODUCTION}

In the past several years ring configurations involving all groups of chromosome have been described in a number of cases (See the reviews by Kistenmacher and Punnett, 1970; Varela and Sternberg, 1969). Among them 19 cases of congenital abnormalities possibly associated with ring $\mathrm{C}$ chromosomes have been reported (Turner et al., 1962; Smith-White et al., 1963; Atkins et al., 1966; Butler et al., 1967; Wurster et al., 1969; Bueno et al., 1969; Kistenmacher and Punnett, 1970; Gacs et al., 1970; Therkelsen et al., 1971; de Chieri et al., 1972; Moore et al., 1973; Zackai and Breg, 1973; Jacobsen et al., 1973; Van den Berghe et al., 1974; Fraisse et al., 1974; Fried et al., 1975; Zdansky et al., 1975). Above all, in recent 8 cases the specific chromosomes from which rings were formed have been precisely identified either by Giemsabanding or fluorescence techniques.

The present paper is concerned with clinical and cytogenetic observations of a mentally and physically retarded male possessing a ring configuration of No. 7 chromosome identified by ASG technique.

\section{CASE REPORT}

The patient is a 19-year-old male born through a spontaneous delivery after a 7-month-gestation complicated by toxemia of pregnancy, to a 29 -year-old para II 
gravida II mother and a 32-year-old father. No complication was noted during the perinatal period. At birth he was $1,180 \mathrm{~g}$ in weight, $30.2 \mathrm{~cm}$ in length, and $12.0 \mathrm{~cm}$ in chest circumference. During the infantile period, his motor and mental development was slow, i.e., standing, walking, and talking were delayed about 6 months as compared with the corresponding child of normal development. At age 4 he referred to our hospital because of suspected psychomotor retardation and delayed speech development, but no conclusive etiological diagnosis was made.

Throughout the years of development the body length and weight have consistently been below the third percentile. At age 19 he was reexamined at the Kyushu University Hospital for the evaluation of mental and physical retardation.

\section{FAMILY HISTORY}

One of his two elder brothers was born through a difficult delivery and died 3 months after birth, with no major malformation. Another brother was normal somatically and mentally. The mother was exposed to the atomic bomb about 4 $\mathrm{km}$ away from the hypocenter in Nagasaki 9 years prior to the patient's gestation, but not to toxic agents or drugs before or during pregnancy. His father has no history of radiation or any unusual medication. There was no known parental consanguinity. No somatic and mental abnormalities were apparent in the other family members.

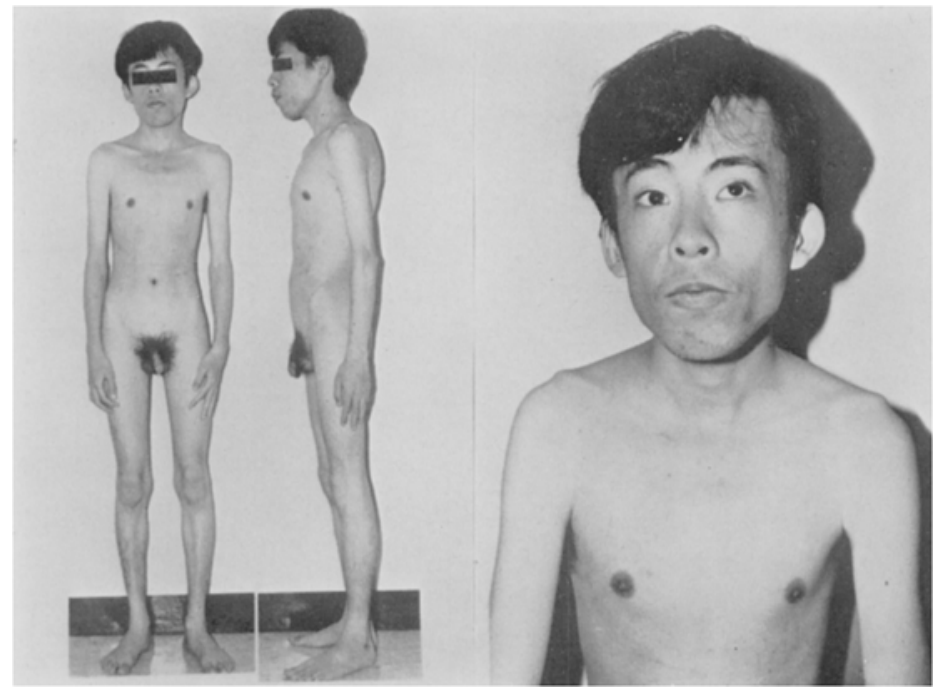

(a)

(b)

Fig. 1. The patient at 19-year-old showing thin, slender and well-proportional somatotype with mild kypholordosis and pectus carinatum (a), and showing bilateral epicanthal folds and strabismus sursumdivergence (b). 


\section{OBJECTIVE FINDINGS}

Physical examination revealed a very thin and slender boy, weighing $23.2 \mathrm{~kg}$, $143 \mathrm{~cm}$ (the length below pubes $72 \mathrm{~cm}$, arm span $143 \mathrm{~cm}$ ) in height (below the third percentile), showing a well-proportional somatotype (Fig. 1a). The following major and minor abnormalities were noted: bilateral slight epicanthal folds, long and thin fingers, high-arched palate, delayed dentition, strabismus sursumdivergence of the left eye, hyperplastic gingiva, mild pectus carinatum, spontaneous Babinski position of the bilateral feet, and mild pes excavatus (Fig. 1b). In addition three hemangiomatous nevi were noted at the left temporo-auricular region (the second and third trigeminal area), being 3 by $2 \mathrm{~cm}, 1.5$ by $1.5 \mathrm{~cm}$ and 1.0 by $1.0 \mathrm{~cm}$ in size. 'Cafe-aulait-like' pigmental spots were sporadically seen in the whole body.

Neurological examination revealed positive Babinski sign and hyperreflexia, but no laterality was seen. Eye movement was clumsy, and extreme movement elicited a holizontal nystagmus occasionally. Bilateral slight cataracta was disclosed by means of a slit-lamp. Optic discs were atrophic with slight pallor, but neither retinal angioma nor discoloration was seen. Development of the penis and testis was within normal limits, and penis erection was present. Muscle tone was normal, and a slight hyperextensibility of the joints was noted. WAIS test gave an I.Q. less than 60 .

\section{LABORATORY INVESTIGATIONS}

Radiographic examination of the cranium showed normal findings without abnormal calcification, and spine was normal except for mild kypholordosis. The metaphyseal lines of the bones were closed and the carpal bones were already matured. Urography was normal, cerebral angiography revealed no abnormal findings and brain scanning gave a normal figure, but electroencephalography showed a very slight functional abnormality with some diffuse 4-7 cps activity, but no focal pathology nor paroxysmal activity was found.

Blood and urine chemistry, hematological indices, gas analyses, serological tests, immunoelectrophoretic pattern, renal function tests and electrocardiogram were all within normal limits except for a slight proteinuria. Thin layer starch gel electrophoresis of the hemoglobin showed the normal adult pattern (no increase in $\mathrm{HbF}$ and $\mathrm{HbA}_{2}$ levels). Levels of $\mathrm{CPK}, \mathrm{Cu}$ and ceruloplasmin in serum were all within normal

Table 1. Blood groups and haptoglobin type of the patient and his parents.

\begin{tabular}{|c|c|c|c|c|c|c|c|c|c|c|c|}
\hline & $\mathrm{ABO}$ & MNSs & Rhesus & Duffy & Lewis & Kell & $\mathbf{P}$ & $\mathrm{I}$ & Webb & Lutheran & Hp \\
\hline Patient & $\mathrm{A}_{1}$ & MNss & ccDEE & $\mathrm{Fy}(\mathrm{a}+)$ & $\operatorname{Le}(a-)$ & $\mathrm{kk}$ & $\mathrm{P}$ & I & $\mathrm{wb}(-)$ & $\operatorname{Lu}(a-b+)$ & $2-1$ \\
\hline Mother & $\mathrm{O}$ & Nss & $\mathrm{ccDEe}$ & Fy $(a+)$ & Le $(a-)$ & $\mathrm{kk}$ & $\mathrm{P}$ & I & $\mathrm{wb}(-)$ & $\operatorname{Lu}(a-b+)$ & $2-2$ \\
\hline Father & $\mathrm{A}_{1}$ & Mss & CCDEE & Fy $(\mathrm{a}+)$ & $\operatorname{Le}(\mathrm{a}-)$ & $\mathrm{kk}$ & $\mathrm{P}$ & I & $\mathrm{wb}(-)$ & $\operatorname{Lu}(a-b+)$ & $2-1$ \\
\hline
\end{tabular}


Table 2. Karyotype analysis of the patient and his mother.

\begin{tabular}{|c|c|c|c|}
\hline \multicolumn{2}{|l|}{ Patient } & \multicolumn{2}{|l|}{ Mother } \\
\hline Karyotype & $\begin{array}{l}\text { No. of } \\
\text { cells }\end{array}$ & Karyotype & $\begin{array}{l}\text { No. of } \\
\text { cells }\end{array}$ \\
\hline $45, \mathrm{XX},-\mathrm{C}$ & 6 & 45 (random loss) & 7 \\
\hline 45 (random loss) & 5 & $46, \mathrm{XX}$ & 86 \\
\hline $46, X Y$ & 1 & $46, X X, r(D)$ & 1 \\
\hline $46, X Y, r(C)$ & 140 & $46, \mathrm{XX}, \mathrm{t}(\mathrm{Dq}-; \mathrm{Cq}+)$ & 1 \\
\hline $46, X Y, R(C)^{*}$ & 8 & $46, X X$, inv (B) & 1 \\
\hline $47, \mathrm{XY}, \mathrm{r}(\mathrm{C}),+\mathrm{r}(\mathrm{C})$ & 1 & $47, \mathrm{XX},+\mathrm{C}$ & 3 \\
\hline $47, X Y, R(C),+R(C)^{*}$ & 1 & $47, \mathrm{XX},+\mathrm{C}$, inv (3), ace & 1 \\
\hline Total cells & 162 & & 100 \\
\hline
\end{tabular}

Note: $\mathrm{R}$ indicates double-sized dicentric ring.

* See Fig. 3.

limits. To the insulin induced hypoglycemia, pituitary growth hormone responded well. Basal levels of FSH and LH was high, and response to the FSH-RH and LHRH stimulations were prolonged. Thyroid function tests indicated euthyroidism. Circadian rhythm of cortisol and metopiron test were normal.

Dermatoglyphic analysis of the finger tips revealed the following findings: left I whorl, II radial loop, III ulnar loop, IV ulnar loop, V double loop; right I whorl, II ulnar loop, III radial loop, IV ulnar loop, V ulnar loop; and total finger ridge count was rather low.

Blood groups and haptoglobin type analyses revealed no discrepancy (Table 1).

\section{CYTOGENETIC STUDIES}

Chromosome analyses were made for the lymphocytes cultured from the peripheral blood of the patient and his parents and for the bone marrow aspiration specimen of the patient. Banding patterns of the chromosomes were analyzed based on the ASG method of Sumner et al. (1971). The results obtained are summarized in Table 2 .

The patient's cells had modal number of 46 chromosomes, and in the majority of the cells, one of 46 chromosomes showed a ring configuration. This was judged to involve one of group $\mathrm{C}$ chromosomes, on the basis of the finding that a submetacentric one among group $\mathrm{C}$ chromosomes was missed. In most of the cells the aberrant chromosome appeared to be a single monocentric ring. An analysis of banding patterns of the chromosomes from 7 cells revealed that all the chromosomes had normal G-band and could be paired except for No. 7 chromosomes (Fig. 2). The single No. 7 chromosome also had normal G-band, and the ring chromosome was almost identical with that of the No. 7 in banding pattern. It was thus concluded that this ring chromosome was derived from a No. 7 chromosome. In a small number of the cells, the ring differed from this form in either size or morphology. As shown 


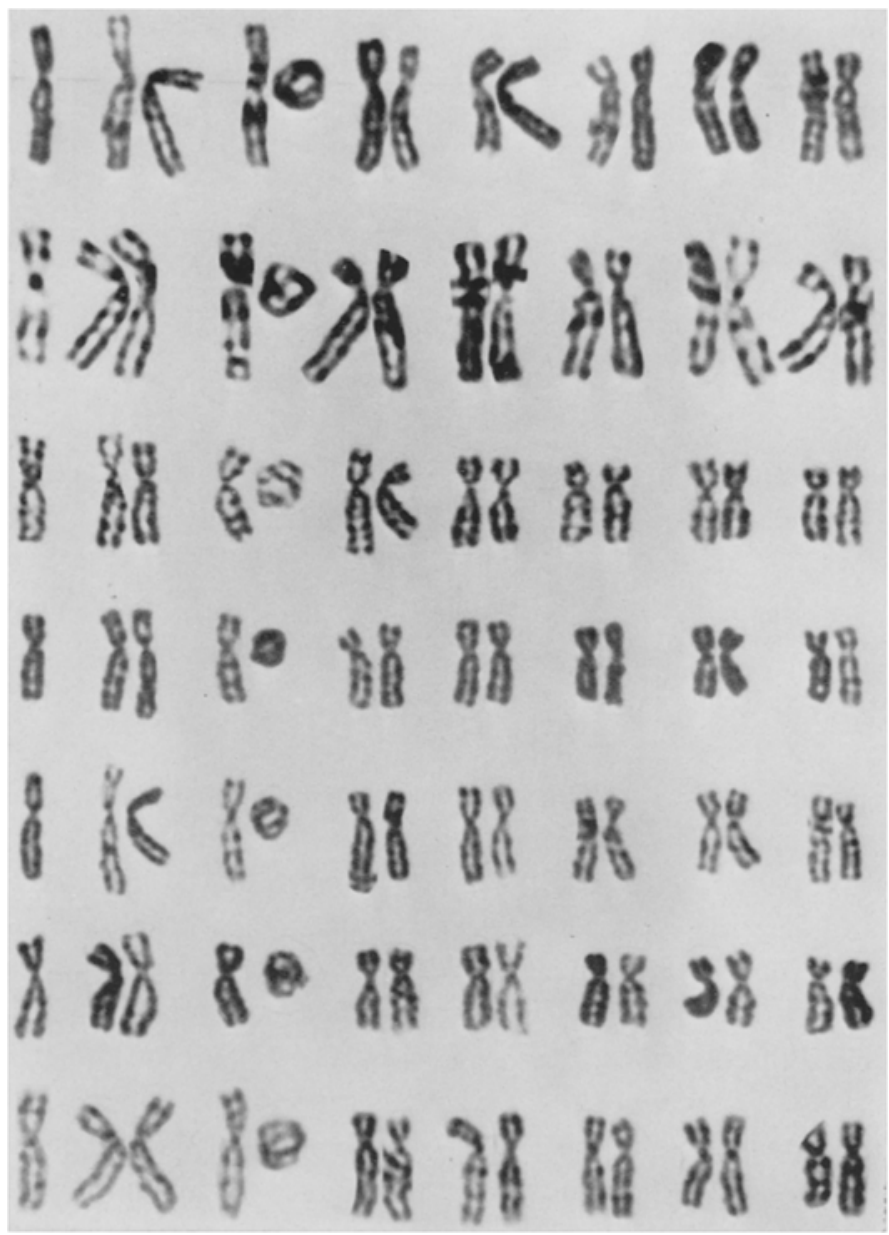

Fig. 2. G-banding patterns of the C-group chromosomes from 7 karyotypes of the patient, showing the typical ring chromosomes involving No. 7 chromosomes.

in Fig. 3, these cells included those with a double-sized dicentric ring and those with double-sized dicentric interlocking rings.

Cultured leucocytes from his father showed normal karyotype, but those from his mother showed some types of structural chromosome abnormalities: ring formation, reciprocal translocation, pericentric inversion and acentric fragmentation.

\section{DISCUSSION}

In a mentally and physically retarded male with various major and minor somatic abnormalities, ring configuration of a No. 7 chromosome was ascertained.

In comparing the phenotypes of the 19 patients with ring $\mathrm{C}$ chromosomes re- 


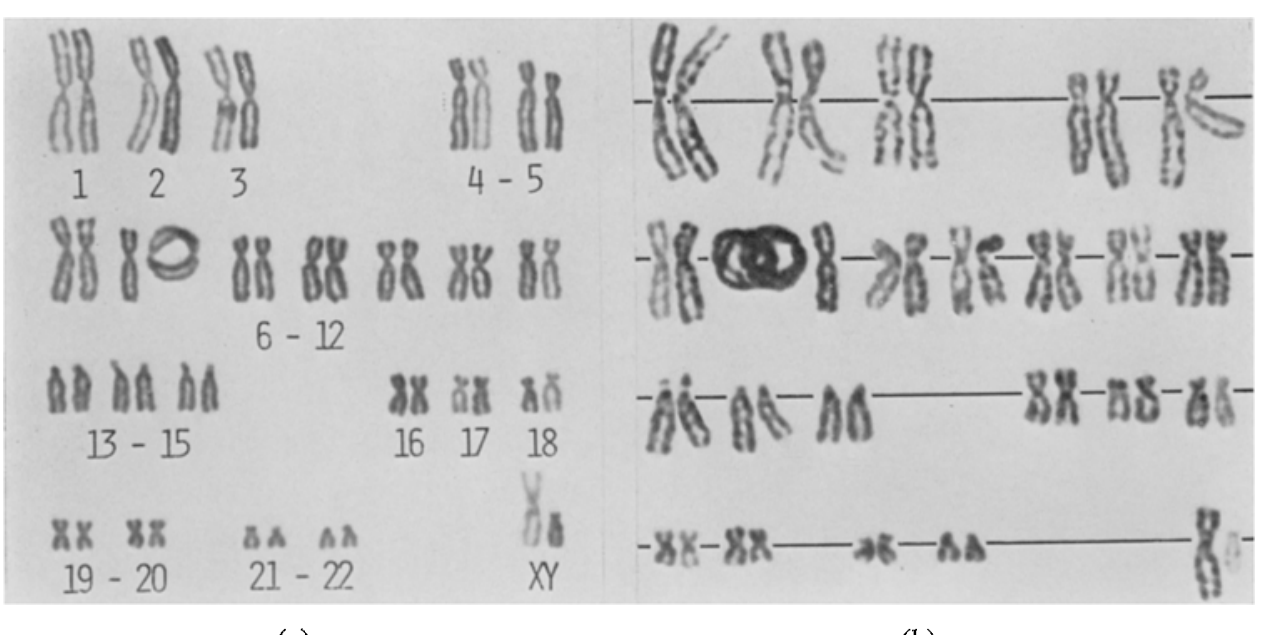

(a)

(b)

Fig. 3. Two karyotypes from the patient including a double-sized dicentric ring (a) and double-sized interlocking dicentric rings (b).

ported in the literatures thus far and the present case (Table 3), clinical manifestations vary widely from case to case. Prominent features most frequently observed in these cases are short stature, mental retardation and microcephaly. Whereas those findings are marked also in several other types of chromosome abnormality syndromes and not characteristic features of the individuals with the ring $\mathrm{C}$ chromosome.

Recently, with banding techniques, it has been possible to identify the affected chromosome, and three cases with ring C6 chromosome (Moore et al., 1973; Van den Berghe et al., 1974; Fried et al., 1975), two with ring C7 (Zackai and Breg, 1973) and three with ring C9 (Jacobsen et al., 1973; Fraisse et al., 1974; Zdansky et al., 1975) have been reported. Clinical findings of the three individuals with ring 7 chromosome, two reported by Zackai and Breg and the present case, were markedly different, and the only findings in common in these three are microcephaly, short stature and hemangioma on the forehead. As to the cases with ring 6 or 9 chromosome, phenotypic expressions also vary widely despite they have same ring chromosomes. Such phenotypic variations may be explicable by difference in quantity of the chromosome material deleted in the process of ring formation, and difference in stability of the ring chromosome during the embryogenesis.

The high incidence of the ring $C$ chromosome in the patient's somatic cells and the absence of this aberration in those of his parents suggest a possibility that the ring had been formed in germ cells of one of the parents. In this connection, it may be noted that 9 years before the patient's birth his mother was exposed to the atomic bomb at a place of about $4 \mathrm{~km}$ from the hypocenter in Nagasaki, and had structural chromosomal aberrations in $4 \%$ of her peripheral leukocytes. This frequency corresponds to that among the reported cases of the survivors exposed within $1,400 \mathrm{~m}$ 
Table 3. Summary of reported cases with ring $\mathbf{C}$ chromosome.

\begin{tabular}{|c|c|c|c|c|c|c|c|c|}
\hline \multirow{2}{*}{$\begin{array}{l}\text { Case } \\
\text { No.* }\end{array}$} & \multirow{2}{*}{ Age } & \multirow{2}{*}{ Sex } & \multirow{2}{*}{ Stature } & \multirow{2}{*}{ I.Q. } & \multirow{2}{*}{ Karyotype } & \multicolumn{2}{|c|}{ Parental age } & \multirow{2}{*}{$\begin{array}{c}\text { Karyotypes } \\
\text { of parents }\end{array}$} \\
\hline & & & & & & Mother & Father & \\
\hline 1. & $12 y$ & $\mathbf{M}$ & Short & 30 & $\begin{array}{l}45, X Y,-C / \\
46, X Y, r(C)\end{array}$ & 24 & 26 & \\
\hline 2. & & M & & & $46, X Y, r(C)$ & & & Normal \\
\hline 3. & $8 \mathrm{y} 6 \mathrm{~m}$ & M & Short & 16 & $46, X Y, B p+, r(C)$ & 37 & 39 & Normal \\
\hline 4. & $2 y 6 \mathrm{~m}$ & $\mathbf{M}$ & Short & Low & $46, X Y, r(C)$ & 24 & 26 & Normal \\
\hline 5. & $5 \mathrm{~m}$ & $\mathrm{~F}$ & $52 \mathrm{~cm}$ & & $46, X X, r(C)$ & & & \\
\hline 6. & $2 y$ & $\mathbf{M}$ & $47 \mathrm{~cm}$ & Low & $46, X Y, r(C)$ & 33 & 33 & Normal \\
\hline 7. & $4 y 6 \mathrm{~m}$ & $\mathbf{M}$ & $87.5 \mathrm{~cm}$ & Low & $46, X Y, r(C)$ & 24 & 26 & Normal \\
\hline 8. & $2.5 \mathrm{~m}$ & $\mathbf{M}$ & $58 \mathrm{~cm}$ & & $46, X Y, r(C)$ & 21 & 21 & Normal \\
\hline 9. & $2 y$ & $\mathbf{F}$ & $82 \mathrm{~cm}$ & Low & $46, X X, r(C)$ & & & Normal \\
\hline 10. & $17 y$ & M & $159 \mathrm{~cm}$ & 28 & $46, X Y, r(C)$ & 36 & 37 & Normal \\
\hline 11. & $3 \mathrm{~m}$ & $\mathbf{F}$ & & & $46, X X, r(C)$ & 25 & 37 & Mother: \\
\hline 12. & $2 \mathrm{y} 6 \mathrm{~m}$ & F & Short & $\begin{array}{r}\text { C.Q.: } \\
69\end{array}$ & $46, X X, r(6)$ & 26 & 27 & $\begin{array}{l}\text { normal } \\
\text { Normal }\end{array}$ \\
\hline 13. & $23 \mathrm{~m}$ & $\mathbf{M}$ & $82 \mathrm{~cm}$ & Low & $46, X Y, r(7)$ & 35 & 40 & Normal \\
\hline 14. & $8 \mathrm{y} 7 \mathrm{~m}$ & $\mathrm{M}$ & $113.5 \mathrm{~cm}$ & 97 & $46, X Y, r(7)$ & 32 & 34 & Normal \\
\hline 15. & $22 y$ & $F$ & $147 \mathrm{~cm}$ & Low & $46, X X, r(9)$ & 38 & 42 & Normal \\
\hline 16. & $20 \mathrm{~m}$ & M & $74.5 \mathrm{~cm}$ & & $46, X Y, r(6)$ & 26 & 27 & Normal \\
\hline 17. & $3 \mathrm{~m}$ & M & $54 \mathrm{~cm}$ & Low & $46, X Y, r(9)$ & 29 & 36 & Normal \\
\hline 18. & $2 \mathrm{y} 6 \mathrm{~m}$ & $\mathbf{M}$ & & Low & $46, X Y, r(6)$ & 24 & 27 & \\
\hline 19. & $12 y$ & M & $130 \mathrm{~cm}$ & Low & $46, X Y, r(9)$ & 21 & 29 & Normal \\
\hline 20. & $19 y$ & $\mathrm{M}$ & $143 \mathrm{~cm}$ & Low & $46, X Y, r(7)$ & 29 & 32 & See text \\
\hline
\end{tabular}

* Reported by: 1, Turner et al., 1962; 2, Smith-White et al., 1963;3 and 4, Atkins et al., 1966; 5, Butler et al., 1967; 6, Wurster et al., 1969; 7, Bueno et al., 1969; 8, Kistenmacher and Punnett, 1970; 9, Gacs et al., 1970; 10, Therkelsen et al., 1971; 11, de Chieri et al., 1972; 12, Moore et al., 1973; 13 and 14, Zackai and Breg, 1973; 15, Jacobsen et al., 1973; 16, Van den Berghe et al., 1974; 17, Fraisse et al., 1974; 18, Fried et al., 1975; 19, Zdansky et al., 1975; and 20, the present paper.

(estimated dose, 200-299 rad) in Nagasaki 20 years afterwards (Bloom et al., 1966). Air does curves proved that subjects who were exposed 3,000-3,999 $\mathrm{m}$ from the hypocenter in Nagasaki received an estimated dose of less than one rad (Bloom et al., 1966). According to Neriishi (1974), the rate of chromosomal aberrations discovered in the peripheral leukocytes of subjects who were exposed at distances of 2,500-3,500 $\mathrm{m}$ was less than $1 \%$, being not significantly different from that in the non-exposed subjects. In view of these reports, it is considered that the dose the mother received was probably not sufficient to induce chromosomal aberration and there might be another factor that caused the chromosome aberration in the mother's germ cells.

Monocentric ring formation arises from two breaks in the same chromosome on both sides of the centromere, and then the edges rejoin to form a ring including centromere, and an acentric fragment remains.

Double-sized dicentric rings and interlocking rings found in a small number of cells of the present case are presumed to be derived from the division of the chromosomes showing the rotational coiling, which must be limited to a $180^{\circ}$ half and $360^{\circ}$ 


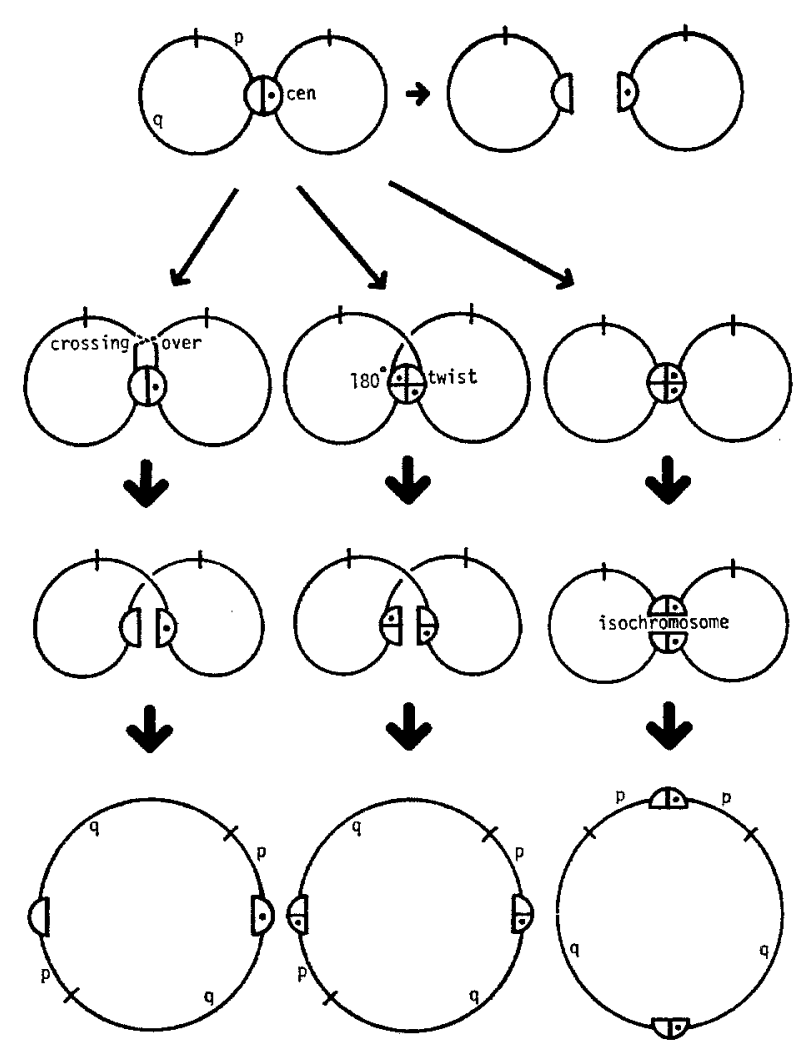

Fig. 4. Presumed mechanism of the formation of double-sized dicentric ring.

full axis twist respectively. The double-sized dicentric ring is presumed to be formed by one of the three ways: (1) crossover occurring between sister chromatids in the usual-sized ring (McClintock, 1938; Schwartz, 1953), (2) a $180^{\circ}$ half twist of the plane of the chromosome splitting at the centromere (Smith-White et al., 1963), and (3) the same way of isochromosome formation (Fig. 4). The banding patterns of the former two are expected to exhibit radial symmetry, and the third one bilateral symmetry.

Double-sized interlocking dicentric rings are derived from the division of doublesized dicentric rings formed by either of the first two mechanisms, because doublesized dicentric rings show $360^{\circ}$ full twist after their formation. Interlocking monocentrics as well are presumed to be derived from the division of a normal-sized ring upon $360^{\circ}$ full twist at the centromere. When double-sized dicentric or interlocking ring(s) formation occurs, one of the daughter cells receives 46 or 47 chromosomes with the ring(s) at cell division, and the other 45 chromosomes with no ring. The findings of 6 cells with $45, \mathrm{XY},-\mathrm{C}, 8$ cells with double-sized dicentric ring and two with interlocking rings in the present case are thus readily explained by these mechanisms. 
proving the manuscript. We also thank Dr. H. B. Hamilton for critically reading the manuscript. The valuable comments of Drs. S. Neriishi and A. A. Awa are gratefully acknowledged. We are indebted to Dr. S. Ikemoto for blood group and haptoglobin analyses.

\section{REFERENCES}

Atkins, L., Pant, S. S., Hazard, G. W. and Quellette, E. M. 1966. Two cases with a C-group ring autosome. Ann. Hum. Genet. 30: 1-6.

Bloom, A. D., Neriishi, S., Kamada, M., Iseki, T. and Keehn, R. J. 1966. Cytogenetic investigation of survivors of the atomic bombings of Hiroshima and Nagasaki. Lancet ii: 672-674.

Bueno, M., del Amo, A. and Hermida, F. 1969. Primordial dwarfism and mental deficiency associated with a group $\mathrm{C}$ annular chromosome. Genet. Iber. $21: 63-80$.

Butler, L. J., France, N. E. and Jacoby, N. M. 1967. An infant with multiple congenital anomalies and a ring chromosome in group C (X-6-12). J. Med. Genet. 4: 295-298.

de Chieri, P. R., Albores, J. M., Cosin, A. and Cosin, J. M. 1972. A human ring C chromosome associated with multiple congenital abnormalities. J. Med. Genet. 9: 239-242.

Fried, K., Rosenblatt, M., Mundel, G. and Krikler, R. 1975. Mental retardation and congenital malformations associated with a ring chromosome 6. Clin. Genet. 7: 192-196.

Fraisse, J., Lauras, B., Ooghe, M. J., Freycon, F. and Rethoré, M. O. 1974. A propos d'un cas de chromosome 9 en anneau. Identification par denaturation ménagée. Ann. Génét. 17: 175-180.

Gacs, G., Schuler, K. and Sellyei, M. 1970. Familial occurrence of congenital malformations and ring chromosome (46, XX, Cr). J. Med. Genet. 7: 177-179.

Jacobsen, P., Mikkelsen, M. and Rosleff, F. 1973. A ring chromosome, diagnosed by quinacrine fluorescence as No. 9 in a mentally retarded girl. Clin. Genet. 4: 434-441.

Kistenmacher, M. L. and Punnett, H. H. 1970. Comparative behavior of ring chromosomes. Am. J. Human Genet. 22: 304-318.

McClintock, B. 1938. The production of homozygous deficient tissues with mutant characteristics by means of the aberrant mitotic behavior of ring-shaped chromosomes. Genetics 23: 315-376.

Moore, C. M., Heller, R. H. and Thomas, G. H. 1973. Developmental abnormalities associated with a ring chromosome 6. J. Med. Genet. 10: 299-303.

Neriishi, S. 1974. Personal communication.

Schwartz, D. 1953. Evidence for sister strand crossing over in maize. Genetics 38: 251-260.

Smith-White, S., Peacock, W. J., Turner, B. and den Dulk, G. M. 1963. A ring chromosome in man. Nature 197: 102-103.

Sumner, A. T., Evans, H. J. and Buckton, R. A. 1971. New technique for distinguishing between human chromosomes. Nature New Biol. 232: 31-32.

Therkelsen, A. J., Møller, B. and Henningsen, K. 1971. A group-C ring chromosome in a mentally deficient male. J. Med. Genet. 8: 227-230.

Turner, B., Jennings, A. N., den Dulk, G. M. and Stapleton, T. 1962. A self-perpetuating ring chromosome. Med. J. Aust. 2: 56-58.

Van den Berghe, H., Fryns, J. P., Cassiman, J. J. and David, G. 1974. Chromosome 6 en anneau. Caryotype 46, XY, r(6)/45,XY, -6. Ann. Génét. 17: 29-35.

Varela, M. A. and Sternberg, W. H. 1969. Ring chromosomes in two infants with congenital malformations. J. Med. Genet. 6: 334-341.

Wurster, D., Pomeroy, J., Benirsohke, K. and Hoefnagel, D.1969. Mental deficiency and malformations in a boy with a group C ring chromosome: $46, \mathrm{XY}, \mathrm{Cr}$. J. Ment. Defic. Res. 13: 184-190.

Zackai, E. H. and Breg, W. R. 1973. Ring chromosome 7 with variable phenotypic expression. Cytogenet. Cell Genet. 12: 40-48.

Zdansky, R., Andrle, M., Bühler, D., Tsuchimoto, T., Mayr, W. R. and Rett, A. 1975. Irregular phenotypic expression of ring chromosomes. Humangenetik 26: 193-198. 